\title{
Analisis Volatilitas Harga Daging Sapi Sebelum Sampai Dengan Sesudah Hari Besar Agama di Kota Jambi
}

\author{
Firmansyah*, Afriani H, Wahyu Aji Paiso \\ Fakultas Peternakan Universitas Jambi \\ *Correspondence email: firmansyah_fapet@yahoo.co.id
}

\begin{abstract}
Abstrak. Penelitian ini bertujuan untuk menganalisis tingkat volatilitas harga daging sapi sebelum puasa (H-7) sampai dengan sesudah lebaran $(\mathrm{H}+7)$ di Kota Jambi, dan menyusun model ramalannya. Penelitian ini memakai metode survey kepada pedagang daging sapi di pasar Angso Duo Kota Jambi. Analisis yang digunakan untuk menghitung volatilitas harga daging sapi adalah analisis model ARCH (Autoregressive Conditional Heteroscedastic) dan Analisis model GARCH (Generalized Autoregressive Conditional Heteroscedasticity). Rata-rata harga daging sapi selama periode sebelum puasa (H-7) sampai dengan sesudah lebaran $(\mathrm{H}+7)$ di Kota Jambi adalah Rp.124.147,-- per kg dengan harga tertinggi Rp.150.000 dan terendah 110.000,- per kg. Volatilitas harga daging sapi selama periode sebelum puasa $(\mathrm{H}-7)$ sampai dengan sesudah lebaran $(\mathrm{H}+7)$ di Kota Jambi yang tertinggi pada menjelang hari Raya Idul Fitri (lebaran). Model $A R C H$ dan GARCH dapat meramal nilai harga daging sapi ke depan.
\end{abstract}

Kata Kunci: Volatilitas; Harga Daging Sapi; Model ARCH-GARCH

Abstract. This study aims to analyze the level of beef price volatility before fasting $(D-7)$ to after Eid $(H+7)$ in Jambi City, and compile a forecast model. This study used a survey method for beef traders in the Angso Duo market, Jambi City. The analysis used to calculate the volatility of beef prices is the ARCH (Autoregressive Conditional Heteroscedastic) model analysis and the GARCH (Generalized Autoregressive Conditional Heteroscedasticity) model analysis. The average price of beef during the period before fasting (D-7) to after Eid $(H+7)$ in Jambi City was IDR 124,147 per $\mathrm{kg}$ with the highest price of IDR 150,000 and the lowest was 110,000 per $\mathrm{kg}$. The volatility of beef prices during the period before fasting $(D-7)$ to after Eid $(H+7)$ in Jambi City is the highest before Eid al-Fitr (Eid). ARCH and GARCH models can predict the future value of beef prices.

Keywords: Volatility; Beef Prices; ARCH-GARCH Model

\section{PENDAHULUAN}

Memasuki Bulan Suci Ramadhan dan Hari Raya Idul Fitri, harga daging sapi mengalami kenaikan signifikan di sejumlah pasar tradisional yang ada di Kota Jambi. Kenaikan harga daging sapi disebabkan meningkatnya permintaan beberapa hari menjelang Bulan Suci Ramadhan dan Hari Raya Idul Fitri. Selain itu, penyebab kenaikan harga daging sapi dikarenakan dari pemasok juga turut naik, sehingga pedagang pun terpaksa menyesuaikan dengan kondisi harga yang dibeli.

Biasanya permintaan terhadap daging sapi oleh di masyarakat menguat sehari sebelum puasa Ramadhan, sehingga harganya meningkat. Namun di pertengahan puasa Ramadhan permintaan dan harganya akan menurun dan baru akan menguat lagi seminggu menjelang Hari Raya Idul Fitri, kemudian kembali turun setelah Hari Raya berlalu

Fenomena terjadinya kenaikkan dan penurunan atau volatilitas harga daging sapi sebelum sampai dengan sesudah Hari Besar Agama sangat menarik untuk diteliti. Volatilitas harga daging sapi disebabkan oleh ketidakstabilan yaitu instability antara supply-demand, dimana hal itu akan terlihat keseimbangan pasar tidak akan terjadi. Menurut Huchet dan Bourdon (2011), volatilitas harga akan dapat meningkat jika terjadi fluktuasi harga yang terlalu tinggi dan harga tersebut sulit diprediksi atau bersifat unpredictable. Ditambahkan
Lepetit dan Isabelle Piot (2011), akibat dari tingginya volatilitas harga, akan menyebabkan harga barang semakin tidak pasti terutama pada masa depan, untuk itu kebijakan pemerintah untuk menjaga tingkat stabilitas harga barang sangat diperlukan.

Fluktuasi harga daging sapi sebelum sampai dengan sesudah hari besar agama menggambarkan volatilitas. Menurut Pipit (2019), nilai volatilitas besar atau kecil menggambarkan seberapa besar tingkat risiko yang akan dihadapi pada masa yang akan datang. Dampak negatif dari volatilitas harga daging sapi yang tinggi atau berlebihan jika pemerintah tidak cepat mengantisipasi kondisi tersebut maka menyebabkan risiko yang harus ditanggung oleh produsen dan pedagang semakin besar

\section{METODE}

Analisis Volatilitas Harga daging Sapi Sebelum sampai dengan Sesudah Hari Besar Agama di Kota Jambi adalah penelitian yang memakai metode survei. Pengambilan data berlangsung selama sekitar 44 hari yaitu dari sebelum puasa (H-7) sampai dengan sesudah lebaran $(\mathrm{H}+7)$ di pasar angso Duo Kota Jambi.

\section{Model Analisis}

Analisis yang digunakan untuk menghitung volatilitas harga daging sapi sebelum dan sesudah hari besar agama di Kota Jambi yaitu 
a. Analisis model ARCH (Autoregressive Conditional Heteroscedastic)

b. Analisis model GARCH (Generalized Autoregressive Conditional Heteroscedasticity).

\section{Uji stasioneritas data}

a. Uji stasioneritas data yang digunakan adalah unit root test

b. Metode Augmented Dickey Fuller Test (ADF Test) dengan taraf nyata $5 \%$.

\section{Uji Autoregressive Integrated Moving Average (ARIMA)}

a. Uji ini dilakukan untuk menentukan model yang akan digunakan dalam uji tahap selanjutnya

b. R-squared terbesar dan menggunakan kriteria Akaike Information Criterion (AIC) dan Schwartz Criterion (SC) yang terkecil (Juanda dan Junaidi, 2012)

\section{Uji Heterokedastisitas ARCH-LM}

a. Menggunakan uji ARCH-LM (Lagrange Multiplier untuk uji Autoregressive Conditional Heteroscedasticity (ARCH)).

b. Uji heterokedastisitas dilakukan guna mengetahui apakah model ARIMA atau persamaan rata-rata terpilih memiliki residual yang heterogen atau efek ARCH

\section{Pemilihan model terbaik}

a. Pendugaan parameter model ARCH-GARCH dan pemilihan model terbaik.

b. Pemilihan model terbaik bertujuan untuk mendapatkan model yang akan digunakan dalam menghitung nilai volatilitas

c. Model GARCH yang digunakan dalam bahan pokok hasil peternakan merupakan model yang melalui beberapa uji yaitu diantaranya adalah uji signifikasi, uji Lagrange Multiplier, uji Ljung Box dan uji Jarque-Bera

\section{HASIL DAN PEMBAHASAN \\ Perkembangan Harga Daging Sapi}

Perkembangan harga daging sapi selama periode sebelum puasa $(\mathrm{H}-7)$ sampai dengan sesudah lebaran $(\mathrm{H}+7)$ di Kota Jambi memiliki kecenderungan meningkat yaitu rata-rata meningkat sebesar $0,31 \%$ per hari. Pada periode sebelum puasa (H-7) sampai dengan hari puasa $(\mathrm{H})$, rata-rata harga daging sapi meningkat sebesar 2,45 \% per hari. Begitupula pada periode sebelum lebaran (H-7) sampai dengan hari lebaran $(\mathrm{H})$, terjadi peningkatan harga daging sapi rata-rata sebesar $2,12 \%$ per hari. Namun pada periode hari lebaran $(\mathrm{H})$ sampai dengan sesudah lebaran $(\mathrm{H}+7)$, terjadi penurunan harga daging sapi rata-rata $-2,73 \%$ per hari, secara rinci tersaji pada Grafik 1.

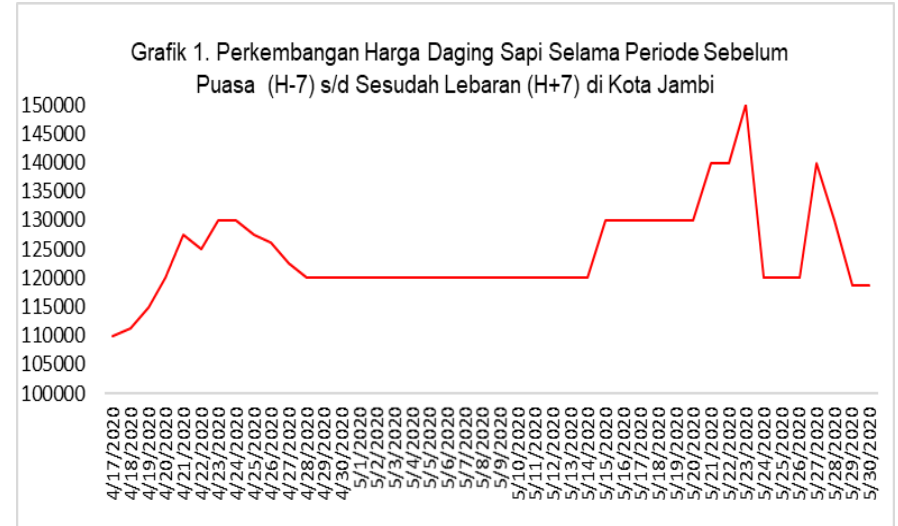

Grafik 1. Perkembangan Harga Daging Sapi

\section{Deskriptif Harga Daging Sapi}

Rata-rata harga barang pangan pokok khusus pangan asal ternak yaitu daging sapi selama periode sebelum puasa (H-7) sampai dengan sesudah lebaran $(\mathrm{H}+7)$ di Kota Jambi adalah sebesar Rp.124.147,- per kg dengan median sebesar Rp.120.000,- per kg. Pada periode tersebut ditemukan harga daging sapi tertinggi Rp.150.000,- per kg, artinya harga daging sapi pada hari $t$ lebih besar dibandingkan pada hari $t-1$. Sedangkan harga daging sapi terendah adalah 110.000 ,- per $\mathrm{kg}$, artinya harga daging sapi pada hari $t$ lebih kecil dibandingkan pada hari $t$-1. Harga daging sapi memiliki nilai Skewness sebesar 1,158 (positif). Artinya bahwa harga daging sapi kecondongan ke kanan atau sebagian besar distribusi harga daging sapi berada di nilai rendah. Selain itu, harga daging sapi memiliki nilai Kurtosis sebesar 4,639 (> 3). Artinya kurva harga daging sapi yang runcing (fat tailed) atau distribusi harga daging sapi tersebut memiliki ekor yang lebih padat dibandingkan dengan sebaran normal.

\section{Uji Stasioneritas Harga Daging Sapi}

Uji stasioneritas data digunakan untuk melihat apakah data mengandung akar-akar unit (unit root) atau tidak. Pada umumnya data runtun waktu (time series) memiliki unsur kecendrungan (trend) yang dapat menjadikan data time series tersebut tidak stasioner. Apabila unsur kecendrungan (trend) tersebut dihilangkan, maka dapat menjadikan kondisi data time series menjadi stasioner. Data time series dikatakan stasioner jika data tersebut tidak mengandung akar-akar unit (unit root) dengan kata lain mean, variance, dan covariant konstan sepanjang waktu. Pengujian akar-akar unit (unit root) dilakukan dengan metode Augmented Dickey Fuller (ADF), yaitu dengan membandingkan nilai $\mathrm{ADF}_{\text {statistik }}$ dengan Mackinnon critical value $1 \%$, $5 \%$, dan $10 \%$, dengan keputusan yaitu data dikatakan stasioner jika nilai $\mathrm{ADF}_{\text {statistik }}$ lebih besar dari Mackinnon critical value $1 \%, 5 \%$, dan $10 \%$, serta nilai probabilitasnya signifikan di bawah $10 \%$, atau sebaliknya (Naiggolan dkk, 2018). Hasil uji stasioneritas harga daging sapi dengan metode ADF sebagai berikut: 
Firmansyah, Afriani H dan Wahyu Aji Paiso, Analisis Volatilitas Harga Daging Sapi Sebelum Sampai Dengan Sesudah Hari Besar Agama di Kota Jambi

Null Hypothesis: D(HARGADAGINGSAPI) has a unit root

Exogenous: Constant, Linear Trend

Lag Length: 2 (Automatic - based on SIC, maxlag=9)

\begin{tabular}{lccc}
\hline \hline & & \\
& & t-Statistic & Prob.* \\
\hline \hline & & \\
Augmented Dickey-Fuller test statistic & -6.817615 & 0.0000 \\
\hline Test critical values: & $1 \%$ level & -4.205004 & \\
& 10\% level & -3.526609 & \\
& -3.194611 & \\
\hline \hline
\end{tabular}

*MacKinnon (1996) one-sided p-values.

Berdasarkan pengujian unit root pada tingkat first difference didapat bahwa nilai $\mathrm{ADF}_{\text {statistik }}$ (6.817615) lebih besar dari critical value $1 \%$ (4.205004) dan probabilitasnya signifikan pada tingkat keyakinan $1 \%$ (0.00000). Hal ini berarti data harga daging sapi selama periode sebelum puasa (H-7) sampai dengan sesudah lebaran $(\mathrm{H}+7)$ di Kota Jambi telah stasioner pada first difference.

\section{Model ARCH Harga Daging Sapi}

Data time series seperti data harga barang kebutuhan pokok hasil peternakan sering kali bervolatilitas. Menurut Carolina dkk (2016), volatilitas merupakan metode statistik untuk mengukur fluktuasi harga barang selama periode tertentu, namun bukan untuk mengukur tingkat harga melainkan mengukur tingkat variasinya selama periode tertentu. Variasi harga dapat menjadi sinyal positif tetapi juga dapat menjadi sinyal negatif apabila variasi harga yang terjadi cukup besar dan tidak dapat diantisipasi oleh pemerintah maupun pelaku ekonomi.

Implikasi data yang bervolatilitas adalah variance dari error tidak constant, dengan kata lain mengalami heteroskedatisitas. Implikasi dari adanya heteroskedatisitas terhadap estimasi OLS tetap tidak bias, tetapi standart error dan interval keyakinan menjadi terlalu sempit sehingga dapat memberikan sense of precision yang salah. Untuk mengetahui mengenai volatilitas, peralatan standar yang digunakan adalah model Autoregressive Conditional Heteroskedasticity Model (ARCH) (Engle, 1982). Model ini menganggap variance yang tidak constant (heteroskedatisitas) bukan suatu masalah, tetapi justru dapat digunakan untuk modeling dan peramalan.

Dependent Variable: HARGADAGINGSAPI

Method: ML ARCH - Normal distribution (BFGS / Marquardt steps)

$\mathrm{GARCH}=\mathrm{C}(3)+\mathrm{C}(4) * \operatorname{RESID}(-1)^{\wedge} 2$

\begin{tabular}{|c|c|c|c|c|}
\hline Variable & Coefficient & Std. Error & z-Statistic & Prob. \\
\hline $\begin{array}{c}\mathrm{C} \\
\operatorname{AR}(1)\end{array}$ & $\begin{array}{l}124950.4 \\
0.691567\end{array}$ & $\begin{array}{l}4247.000 \\
0.126596\end{array}$ & $\begin{array}{l}29.42086 \\
5.462798\end{array}$ & $\begin{array}{l}0.0000 \\
0.0000\end{array}$ \\
\hline \multicolumn{5}{|c|}{ Variance Equation } \\
\hline $\begin{array}{c}\mathrm{C} \\
\operatorname{RESID}(-1)^{\wedge} 2\end{array}$ & $\begin{array}{r}22946242 \\
0.519236\end{array}$ & $\begin{array}{l}6641759 . \\
0.406710\end{array}$ & $\begin{array}{l}3.454844 \\
1.276674\end{array}$ & $\begin{array}{l}0.0006 \\
0.2017\end{array}$ \\
\hline
\end{tabular}

Berdasarkan hasil analisis terlihat ARCH menunjukkan hasil yang signifikan (prob. sebesar 0,00000 ) berarti kesalahan prediksi (residual) harga daging sapi sebelum sampai dengan sesudah hari besar agama di Kota Jambi dipengaruhi oleh residual kuadrat periode sebelumnya ARCH(1). Namun dengan 
Firmansyah, Afriani H dan Wahyu Aji Paiso, Analisis Volatilitas Harga Daging Sapi Sebelum Sampai Dengan Sesudah Hari Besar Agama di Kota Jambi

memasukkan efek persamaan ARCH ini, apakah kemudian model terbebas dari efek ARCH. Sebelum mengestimasi model ARCH untuk runtun waktu harga daging sapi, biasanya dilakukan pengujian terhadap adanya efek ARCH dalam residual. Jika tidak terdapat efek ARCH dalam residual, maka model ARCH tidak diperlukan.

Heteroskedasticity Test: ARCH

\begin{tabular}{llll}
\hline \hline & & & \\
F-statistic & 0.062385 & Prob. F(1,41) & 0.8040 \\
Obs*R-squared & 0.065328 & Prob. Chi-Square(1) & 0.7983
\end{tabular}

Test Equation:

Dependent Variable: WGT_RESID^2

\begin{tabular}{crrrr}
\hline \hline Variable & Coefficient & Std. Error & t-Statistic & Prob. \\
\hline \hline & & & & \\
C & 1.002117 & 0.416787 & 2.404386 & 0.0208 \\
WGT_RESID^2(-1) & -0.038848 & 0.155536 & -0.249769 & 0.8040 \\
\hline \hline
\end{tabular}

Hasil perhitungan menunjukkan nilai prob sebesar 0,804013 (lebih besar dari 0.05), dengan demikian pada lag (1) secara statistik tidak signifikan. Maka hipotesis H0 diterima dan H1 ditolak, yang berarti varian residual konstan atau dengan kata lain model yang digunakan sudah tidak mengandung efek ARCH.

\section{Model GARCH Harga Daging Sapi}

Dependent Variable: HARGADAGINGSAPI
Method: ML ARCH - Normal distribution (BFGS / Marquardt steps)
GARCH $=\mathrm{C}(3)+\mathrm{C}(4) * \operatorname{RESID}(-1)^{\wedge} 2+\mathrm{C}(5)^{*} \mathrm{GARCH}(-1)$

\begin{tabular}{|c|c|c|c|c|}
\hline \multicolumn{5}{|c|}{$\begin{array}{l}\text { Dependent Variable: HARGADAGINGSAPI } \\
\text { Method: ML ARCH - Normal distribution (BFGS / Marquardt steps) } \\
\text { GARCH }=\mathrm{C}(3)+\mathrm{C}(4) * \operatorname{RESID}(-1)^{\wedge} 2+\mathrm{C}(5) * \mathrm{GARCH}(-1)\end{array}$} \\
\hline Variable & Coefficient & Std. Error & z-Statistic & Prob. \\
\hline $\begin{array}{c}\mathrm{C} \\
\mathrm{AR}(1)\end{array}$ & $\begin{array}{l}121728.2 \\
0.691949\end{array}$ & $\begin{array}{l}2646.292 \\
0.135221\end{array}$ & $\begin{array}{l}45.99954 \\
5.117182\end{array}$ & $\begin{array}{l}0.0000 \\
0.0000\end{array}$ \\
\hline \multicolumn{5}{|c|}{ Variance Equation } \\
\hline $\begin{array}{c}\mathrm{C} \\
\operatorname{RESID}(-1)^{\wedge} 2 \\
\operatorname{GARCH}(-1)\end{array}$ & $\begin{array}{l}2537628 \\
0.404806 \\
0.612306\end{array}$ & $\begin{array}{l}2103215 . \\
0.313541 \\
0.227352\end{array}$ & $\begin{array}{l}1.206547 \\
1.291078 \\
2.693210\end{array}$ & $\begin{array}{l}0.2276 \\
0.1967 \\
0.0071\end{array}$ \\
\hline
\end{tabular}

Hasil analisis terlihat GARCH menunjukkan hasil yang signifikan (prob. sebesar 0,0071), berarti varian kesalahan prediksi (residual) harga daging sapi sebelum
Selain model ARCH, peralatan standar yang digunakan untuk mengetahui volatilitas adalah model Generalized Autoregressive Conditional Heteroskedasticity Model (GARCH) (Bollerslev, 1986). Model ini menganggap variance yang tidak constant (heteroskedatisitas) bukan suatu masalah, tetapi justru dapat digunakan untuk modeling dan peramalan. sampai dengan sesudah hari besar agama di Kota Jambi dipengaruhi oleh varian residual periode sebelumnya GARCH(1). Nilai ARCH juga menunjukkan hasil yang 
Firmansyah, Afriani H dan Wahyu Aji Paiso, Analisis Volatilitas Harga Daging Sapi Sebelum Sampai Dengan Sesudah Hari Besar Agama di Kota Jambi

signifikan (prob. sebesar 0,0000), berarti varian kesalahan prediksi (residual) harga daging sapi dipengaruhi oleh varian residual kuadrat periode sebelumnya GARCH(1).

Heteroskedasticity Test: ARCH

$\begin{array}{llll}\text { F-statistic } & 0.140858 & \text { Prob. F(1,41) } & 0.7094 \\ \text { Obs*R-squared } & 0.147224 & \text { Prob. Chi-Square(1) } & 0.7012\end{array}$

Test Equation:

Dependent Variable: WGT_RESID ${ }^{\wedge}$

Method: Least Squares

\begin{tabular}{crrrr}
\hline \hline Variable & Coefficient & Std. Error & t-Statistic & Prob. \\
& & & & \\
\hline \hline C & 1.037571 & 0.426688 & 2.431684 & 0.0195 \\
WGT_RESID^2(-1) & -0.058451 & 0.155739 & -0.375311 & 0.7094 \\
& & & & \\
\hline \hline
\end{tabular}

Namun dengan memasukkan unsur persamaan GARCH ini, apakah kemudian model terbebas dari efek ARCH. Hasil perhitungan menunjukkan nilai prob sebesar 0.709364 (lebih besar dari 0.05), dengan demikian pada lag (1) secara statistik tidak signifikan. Maka hipotesis H0 diterima, yang berarti varian residual konstan atau dengan kata lain model yang digunakan sudah tidak mengandung efek ARCH.

\section{Volatilitas Harga Daging Sapi}

Volatilitas merupakan ukuran fluktuasi harga selama beberapa periode waktu atau prediksi pergerakan harga selama periode waktu. Volatilitas juga mengacu pada perubahan harga tak terduga tapi masih perlu diperkirakan. Beberapa ukuran volatilitas dan penilaian risiko didasarkan pada deviasi, standar deviasi dan koefisien variasi (Dewi, 2016). Nilai volatilitas harga daging sapi selama periode sebelum puasa (H-7) sampai dengan sesudah lebaran $(\mathrm{H}+7)$ di Kota Jambi dapat dilihat berdasarkan Conditional Standard Deviation (CSD) atau simpangan baku bersyarat. Adapun hasil estimasi nilai volatililitas harga daging sapi berdasarkan CSD dapat dilihat pada Grafik 2 berikut.

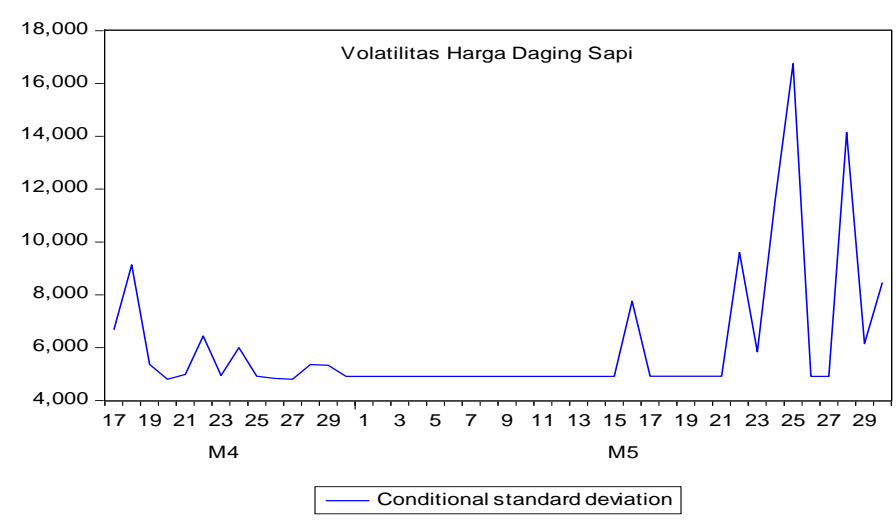

Grafik 2. Volatilitas Harga Daging Sapi

Pada Grafik 2. terlihat bahwa volatilitas harga daging sapi selama periode sebelum puasa (H-7) sampai dengan sesudah lebaran $(\mathrm{H}+7)$ di Kota Jambi yang tertinggi pada menjelang hari Raya Idul Fitri (lebaran). Menurut Sumaryanto (2009) volatilitas yang tinggi dicirikan oleh Conditional Standard Deviation (CSD) yang jauh lebih dari yang lainnya dan dalam grafik ditunjukkan oleh puncak-puncak grafik yang menjulang. Menurut Priyanti dan Ismeth (2014) Seminggu menjelang Hari Raya Idul Fitri (H-7) sampai sehari menjelang Hari Raya Idul Fitri (H-1), kenaikan rata-rata harga eceran daging sapi masing-masing mencapai $20 \%$. Sebaliknya, pada sehari setelah Hari Raya Idul Fitri $(\mathrm{H}+1)$ sampai seminggu setelah Hari Raya Idul Fitri $(\mathrm{H}+7)$, rata-rata harga eceran daging sapi turun sebesar $16 \%$ - 10\%. Ditambahkan Komalawati dkk (2018) volatilitas harga yang terjadi setiap hari raya Idul Fitri adalah sesuatu yang rutin terjadi, 
Firmansyah, Afriani H dan Wahyu Aji Paiso, Analisis Volatilitas Harga Daging Sapi Sebelum Sampai Dengan Sesudah Hari Besar Agama di Kota Jambi

\section{Peramalan dengan Model ARCH untuk Harga Daging Sapi}

Hasil peramalan dengan model ARCH untuk harga daging sapi terlihat bahwa nilai bias proportion sebesar 0.001824 dan covariance proportion 0.414708 . Nilai bias proportion tersebut di bawah 0.2 , sementara nilai covariance proportion mendekati 1 , maka dapat dikatakan bahwa model Autoregressive Conditional Heteroskedasticity Model (ARCH) dapat meramal nilai harga daging sapi ke depan. Hasil penelitian ini sejalan dengan penelitian Burhani dkk (2013), yaitu alternatif model peramalan untuk mengkaji volatilitas harga daging sapi potong di Indonesia adalah model ARCH (1). Hasil peramalan dengan model ARCH untuk harga daging sapi tersaji secara jelas pada Grafik 3.
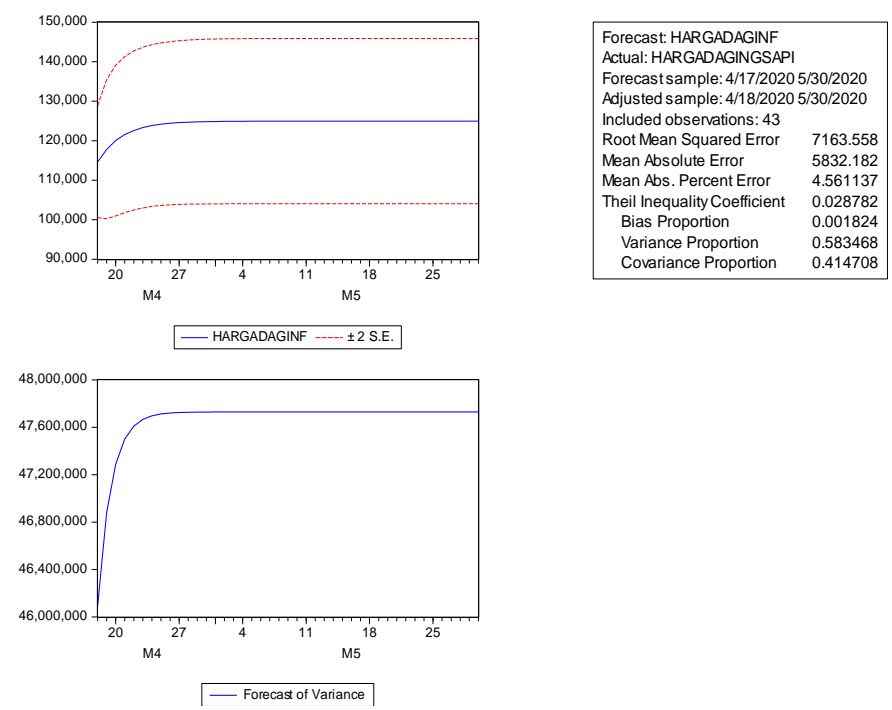

Grafik 3. Peramalan dengan Model ARCH untuk Harga Daging Sapi

\section{Peramalan dengan Model GARCH untuk Harga Daging Sapi}

Hasil peramalan dengan model GARCH untuk harga daging sapi selama periode sebelum puasa $(\mathrm{H}-7)$ sampai dengan sesudah lebaran $(\mathrm{H}+7)$ di Kota Jambi terlihat bahwa nilai bias proportion sebesar 0.179505 dan covariance proportion 0.265556. Nilai bias proportion tersebut di bawah 0.2 , sementara nilai covariance proportion mendekati 1, maka dapat dikatakan bahwa model Generalized Autoregressive Conditional Heteroskedasticity Model (GARCH) dapat meramal harga daging sapi ke depan. Menurut Larasati dkk (2016) model GARCHadalah model yang cocok untuk diterapkan dalam menganalisis dan meramalkan data volatilitas sembilan bahan pokok. Hasil peramalan dengan model GARCH untuk harga daging sapi tersaji secara jelas pada Grafik 4.
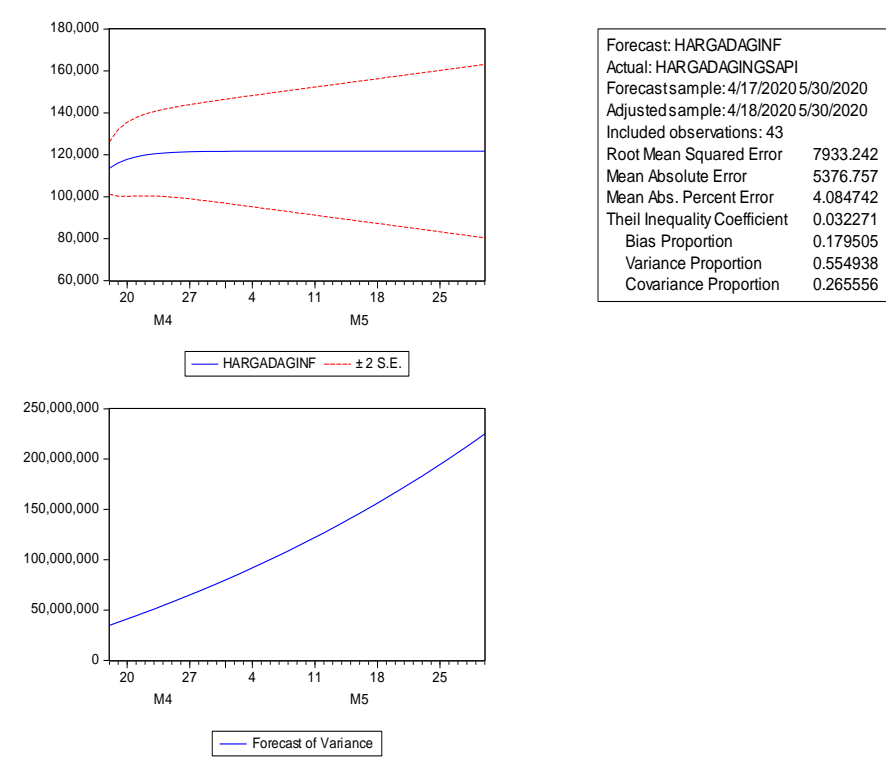
Grafik 4. Peramalan dengan Model GARCH untuk Harga Daging Sapi

\section{SIMPULAN}

1. Volatilitas harga daging sapi selama periode sebelum puasa (H-7) sampai dengan sesudah lebaran $(\mathrm{H}+7)$ di Kota Jambi yang tertinggi pada menjelang hari Raya Idul Fitri (lebaran).

2. Model $A R C H$ dan $G A R C H$ dapat meramal nilai harga daging sapi ke depan

\section{DAFTAR PUSTAKA}

Bollerslev, T. 1986. Generalized Autoregressive Conditional Heteroskedasticity. Journal of Econometrics.31: 307-327

Burhani F.J., A. Fariyanti dan S. Jahroh. 2013. Analisis Volatilitas Harga Daging Sapi Potong dan Daging Ayam Broiler di Indonesia Departemen Agribisnis, Fakultas Ekonomi dan Manajemen, Institut Pertanian Bogor

Carolina, R. A., Mulatsih, S., dan Anggraeni, L. (2016). Analisis Volatilitas Harga dan Integrasi Pasar Kedelai Indonesia dengan Pasar Kedelai Dunia. Jurnal Agro Ekonomi, 34(1), 47-65.

Dewi I. 2016. Price Volatility Analysis in Indonesian Beef Market. Thesis Program Pascasarjana IPB. Bogor.

Engle, R. F. 1982. Autoregressive Conditional Heteroscedasticity with Estimates of ,the Variance of United Kingdom Inflation. Journal of Econometrica. Vol 50: 987-1008.

Huchet, M., \& Bourdon. 2011. Agricultural Commodity Price Volatility: An Overview. Paris: OECD Food, Agriculture and Fisheries Makalahs, No. 52, OECD Publishing

Juanda, B., Junaidi. 2012. Ekonometrika Deret Waktu: Teori dan Aplikasi. Bogor : IPB Press.

Komalawati, Ratna Winandi, Rita Nurmalina, dan Dedi Budiman Hakim. 2018. Dampak Volatilitas Harga Daging Sapi terhadap Industri Pengolahan 
Daging Sapi Skala Mikro di Indonesia. PANGAN, Vol. 27 No. 1 April $2018: 9-22$

Larasati E. N., P. Hendikawati dan Zaenuri. 2016. Analisis Volatility Forecasting Sembilan Bahan Pokok Menggunakan Metode Garch Dengan Program R. UNNES Journal of Mathematics. 5 (1). hal : $90-99$.

Lepetit dan Isabelle Piot. 2011. Price Volatility and Price Leadership in the EU Beef and Pork Meet Market. Workshop on Methods to Analyse Price Volatility. Institute for Prospective Technological Studies (IPTS), Join Research Center (JRC), European Comision. Spain

Naiggolan W, N. Nainggolan dan H. A.H. Komalig. 2018. Analisis Volatilitas Harga Eceran Komoditas Beberapa Pangan Utama di Kota Manado Menggunakan Model ARCH. JURNAL MIPA UNSRAT ONLINE 7 (2) 6 - 11

Pipit, Yudi S.P., dan Evahelda. 2019. Analisis Volatilitas Harga Daging Sapi Di Provinsi Kepulauan Bangka Belitung. Jurnal Ekonomi Pertanian dan Agribisnis (JEPA). Volume 3, Nomor 3 (2019). Hal : 619-630

Sumaryanto. 2009. Analisis volatilitas harga eceran beberapa komoditas pangan utama dengan model ARCH/GARCH. Jurnal Agro Ekonomi Vol. 27 No. 2. Hal: 135-163

Priyanti dan Ismeth. 2014. Perilaku Harga Produk Peternakan Pada Hari Besar Keagamaan Nasional. Analisis Kebijakan Pertanian, Vol. 14 No. 2, Desember 2016: 149-162 